\title{
93 birth, belonging and migrant mothers: narratives of reproduction in feminist migration studies
}

\author{
Irene Gedalof
}

\section{abstract}

Drawing on feminist philosophical accounts of reproduction and initial data acquired through research with migrant mothers in London, this article argues that the role and place of reproduction remains under-theorized within scholarly accounts of women's role in migration processes. Working with an expanded concept of reproduction that includes not only childbirth and motherhood, but also the work of reproducing heritage, culture and structures of belonging, it argues that feminist migration scholars can draw on valuable theoretical resources in order to tell more complicated stories about the place of reproduction in migration, and challenge the often problematic gendered distinctions between travelling and staying put, change and repetition that continue to underpin some of the narrative structures operative in migration studies.

\section{keywords}

migration; reproduction; home; embodiment; mothering 


\section{introduction}

In this article, I argue that scholarly accounts of migration often frame migration as a narrative of dynamism, change, mobility and agency, without questioning the gendered politics of this account. By over-privileging movement, distance and the productive challenges of dislocation, the work that is done at close quarters in the 'reproductive sphere', mainly by women, and in particular by mothers, risks being under-valued and under-theorized. By 'reproductive sphere' I mean both the embodied work of mothering, such as childbirth and childcare, and the work of reproducing cultures and structures of belonging, such as the passing on of culturally specific histories and traditions regarding food, dress, family and other inter-personal relationships. Both these aspects of women's labour tend to be conceptualized in the history of Western thought as being linked to sameness, being, 'mere' repetition, in contrast to the more dynamic or creative generation of difference and becoming that is associated with the public sphere of production. Luce Irigaray has termed this framing of the maternal as the triumph of a 'logos that claims to reduce the power of the maternal back to the same - the Same' (Irigaray in Whitford, 199la: 55). Important critiques of the gendered binary opposition, which is often posited between productive work and reproductive labour, have been developed by feminist philosophical accounts of maternal subjectivity and the reproductive body. But this body of theory has not generally been considered within the field of migration studies, even though feminist migration studies has long included the question of 'home' as an object of inquiry (Webster, 1998; Gray, 1999), and feminist migration researchers have increasingly turned to questions of caring, mothering and family dynamics in recent years (Zontini, 2001, 2004, 2007; Reynolds, 2005; Dyck, 2006; Ryan, 2007, 2008; Baldassar, 2008; Svasek, 2008; Ryan et al., 2009). It is in relation to these questions that feminist philosophical accounts of the maternal might be drawn upon to provide potentially valuable discursive resources for challenging the limitations of stories about migration that continue to work through the binary oppositions between travelling and staying put, novelty and repetition.

For its part, feminist theoretical writing on reproduction has tended to focus more on questions of subjectivity rather than on the collective social identity issues raised by migration and diaspora. It thus tends to keep apart its consideration of the reproductive body and women's subjectivity as mothers, and the ways in which this embodied reproductive work is also related to the re-making of specific cultural and historical collectivities of identity and belonging. It is my aim in this article to bring feminist scholarship on migration and reproduction into dialogue, in ways that might profitably complicate the kinds of stories about reproduction that are told in both fields. 


\section{one narrative of mothering, repetition and difference}

As part of a long-term project to examine migrant women's practices of cultural reproduction, I conducted a pilot study focus group discussion with four firstgeneration migrant women of Sierra Leonean origin in London in 2005. I draw on this material here for a very specific and limited purpose. First, I start from the methodological assumption that any piece of empirical research is a 'meaning-constructing activity' (Borland, 2004: 522), in which the varied and variable positionings, power, intentions and preoccupations of researcher and researched, the specific conditions and circumstances of the research encounter, and the narrative and discursive resources available to all participants in the encounter will affect and inflect the results (Cameron, 2001; Gunaratnam, 2003). Second, therefore, I treat this focus group discussion as one collectively constructed narrative about experiences of migration and ideas of belonging. I am interested in it here, not in order to make any claims of representativity or generalizability in relation to the experiences of a particular community of migrant women, or even of these women. Rather, my approach is more in line with a limited critical discourse analysis in which I am interested in asking what lexical choices and resources (Cameron, 2001: 125) and what interpretive frameworks (ibid.: 126) the group drew on to address the questions they discussed. I am also asking how these choices might feed into producing a particular narrative structure, by which I mean, what kinds of events and activities are foregrounded as starting points, and with what consequences for the further development of the story being told (Jaworski and Coupland, 1999: 32). In particular, because of the theoretical preoccupations I have already suggested, I am interested in how notions of sameness and difference, repetition and change, distance and proximity are evoked and treated in the narrative produced. Despite the limitations of the data, I think that these questions are worth asking, not so much for what they might tell us about the 'authenticity' or representativity of any experiences recounted, but for what they suggest about the possible repertoires of meaning-making that can be involved in talking about reproductive work in the context of migration. Since my concern in this article is not to represent the experiences of any particular group of migrant women but rather to ask what discursive resources (including narrative structures and theories) feminist migration scholars might draw on in framing the questions they ask and the answers they go looking for, I am in a sense staging a brief encounter between my focus group participants and the theories operative in feminist migration studies. One of the conventional uses of focus groups, especially at the beginning of research processes, is to generate data on how the respondents themselves talk about a topic, in order to devise surveys or interview questions that engage with that language (Morgan, 2004: 267). In an admittedly unconventional variation on this move, I am using the data of how respondents 
themselves talk about a topic to ask some questions about the theoretical frameworks that might underpin the research questions that are asked when we think about reproduction and migration. Ronit Lentin (2004) has argued that feminist migration researchers can, through their representational strategies, use their power to name and categorize in ways that constitute migrants as 'other' or as objects of the researcher's gaze. Here, I draw on Lentin's insight to consider how scholarly representational frameworks might operate in relation to making sense of particular aspects of reproductive labour.

My main question for the women in my focus group was what they did to produce a sense of belonging for themselves and their families. All of the women involved were mothers, and it was very much through their subject-positions as mothers that they approached this question. It was through their daily decisions about how to mother - who would look after the children and how, what to feed them, how to dress them, what and how to teach them - that a quite complicated sense of collective belonging in diasporic spaces was negotiated. Listening to these women raised a number of questions for me about the ways in which both the work of mothering and the sphere of cultural reproduction are theorized in migration studies, and whether it makes sufficient space for these kinds of stories.

Two points that emerged in the focus group struck me as particularly significant. The first involved a discussion of the kinds of work the women engaged in during the early years of their migration to the UK, and the childcare arrangements that this necessitated. $N$, who arrived in the UK as a young adult to join her husband, and who had worked as a secondary school teacher in Sierra Leone before arriving here, initiated this part of the discussion by saying:

Because you want to feed your family, you want stability, you'll do anything - clean toilets, anything - you won't find a young man to do that - no one else will give me 3 pounds so why not?

$B$, who arrived from Sierra Leone in the 1960 s as a young married woman, talked about having to leave her daughter with a foster family:

Sometimes I had to have her living with Europeans, and that was very difficult - still, I made an effort to bring her home on weekends so she could adapt to our food - that was difficult, because she wouldn't want to eat it - eventually she got used to it - if she comes to me now, she eats my food without too much fuss.

Similarly, $A$, who arrived in the 1980 s without any siblings to rely on, said:

I had to work full time, and that meant the children went to childminders, we had Ghanaian, Maltese, Nigerian, English childminders. That was difficult - I would have loved them to know the language and culture more. 
1 I am not suggesting the existence of any kind of uniform 'African identity' in using this term; rather, as seen below, this is the language chosen by the participants in the focus group.
In this part of their collective narrative, what begins to emerge is that in pursuit of 'stability' for themselves and their children, these women were prepared to do all sorts of things that were not culturally conventional for them. Like many other migrant women, they took jobs that they were overqualified for or that they had never considered appropriate in the past. They left their children with childminders or even foster families of different backgrounds and cultural origins, so that they could work. This did not stop them from carrying on the work of preserving what they defined as African ${ }^{1}$ identities for their children - cooking African food, taking them to weddings and funerals, teaching them, as $B$ remarked, 'how we do things'. But what was striking to me was that the women evoked the notion of stability both in relation to those reproductive activities that involved what might conventionally be considered continuity, and those that required quite significant change. The need to achieve stability is the narrative starting point for embracing the simultaneous reproduction of an 'African' home and family in the context of diaspora, and the exposure of their children to other homes and family forms. It seemed that the work of making stable homes required accepting changes to these women's conventions of negotiating both public and private spaces. Stability and change seemed to be being evoked, not as the familiar binary opposition, but as part of the same process.

The second point was that everyday acts of embodied reproduction - involving such things as food, clothing, hair - were discussed as sites in which repetition and innovation were inextricably intertwined. Two of the longest and most animated discussions within the focus group involved clothes and hair.

$S$, whose family was originally from Sierra Leone, arrived in the UK from Liberia in the 1960 s as a teenager to attend boarding school. Now divorced with two children, she works as a teacher. Here are some of her interventions in the discussion on clothes:

I think that some mothers get their status through their children and how their children dress .... There's a symbolism there .... .

... My children have to dress in a way that reflects the way they have been brought up take pride in their appearance.

I want them to be appropriate, decent, clean. We've worked, let that be reflected in our children, to show they know that, at a funeral or a wedding, we dress like this.

Fashion might change but you just know that certain fashion isn't appropriate to wear. It's the same idea of what is decent. It can be African or Western costume but has to be of a certain standard. However much style changes you can find something that is acceptable to your own community.

Here, $S$ introduces two elements that I see as significant. The first is the entanglement of embodied practices such as choice of clothing with collective or community identities, that how her children dress reflects, not only on her abilities as a mother, but also on her and her children's place within her 
community. The second is the idea that identifying an underlying continuity or 'sameness' involves engaging with the difference of changing styles and possibilities, an example of what I mean by the intertwining of repetition with innovation.

These elements are further developed in the discussion on hair, where differences emerge between the women on what is at stake in relation to the choices mothers make and their impact on collective identities:

S: Black women will use hairstyles to express our identity. Before, we had to conform to European hair, straightening it ... .

$B$ : It may be my age, but I am worried that we are losing identity through that, losing our cultural heritage by adapting so much or welcoming new trends where Africans think they are being African by adding hair extensions. Once this was just a fashion but now it's a way of life. We aren't showing our children that they can use natural hair without extensions or creams. My fear is, what is it doing to us economically, spending a lot of money on makeup and hair products. We are not thinking, but economically, if you think of women in Africa and they are all depending on hair products from China - it's a multibillion business.

S: I like the fact that I can change my hair overnight.

$N$ : I have lots of wigs. Sometimes it's cheaper to buy a wig than to have plaits done.

$B$ : But what does it do to you culturally?

A: For me, it's a question of choice, that I can pass on to my daughters. I always do my young daughter's hair in plaits, but she knows she can have plaits or other hairstyles later, because she sees that sometimes I wear a wig, sometimes other styles ... .

$N$ : And plaits are still African, even when done with weaves or extensions. It's good that hairstylists have spread in Africa, even out to the countryside, because it creates jobs.

$B$ : But people are spending too much money on this and it's not an African industry ....

That clothes and hair are important performative sites in which culturally specific identities are re-constituted is well-established (Weekes, 1997; Puwar, 2002; Craig, 2006; Tate, 2007). What is interesting to me in these excerpts is that the women were weaving a complicated narrative about the inextricability and inter-dependence of repetition and change in these identity-constituting processes. Which, among the ever-changing fashion items available in Britain, is 'appropriate' wear for an African wedding celebrated in the diaspora? How does one identify the underlying persistent standard of 'what counts as decent' across the impermanence of a global fashion industry? Does the current style for plaits woven with hair extensions signify African-ness, even when those extensions were produced in China? How did this style come to signify 'African-ness'? Should these changes in fashion and hairstyle be understood as a welcome expansion of choice for women and their children in the diaspora and back in Africa, enabling new ways to embody their cultural identities, or does it tie them into a globalized culture that means economic dependency on foreign products and a loss of identity? Like the notion of stability discussed above, 
2 See for example Chambers, 1994, and Ahmed et al., 2003 for a critique of this tendency. discussions of appropriateness and authenticity in these everyday decisions seemed to inaugurate a complex entanglement of past and present, continuity and change. These daily material practices of migrant mothers were not simply about repeating fixed cultural traditions, but rather about actively negotiating difference. But to what degree do the theoretical accounts of reproduction, the household and the domestic that are operative within migration studies create space for accommodating these complexities?

\section{mothering in migration studies}

In under-theorizing reproduction and the domestic, migration studies have historically shared in an over-privileging of movement that risks celebrating rootlessness ${ }^{2}$ rather than attending to the complexities of inhabitance in the context of displacement. Attempts to think home, movement and identity together do exist, yet these are often underpinned by a suggestion that, in order to grasp the fluid and dynamic process of constituting 'home', one needs to move beyond the domestic space of the house, and focus instead on other discursive and institutional sites, such as autobiographical narrative, poetry and music, the state and the nongovernmental organization (Rapport and Dawson, 1998). Without wanting to contest the importance of any of these sites in producing notions of home, it needs to be noted that the domestic space is often simultaneously theorized as problematically fixed to a more limited and limiting notion of belonging. Thus the domestic is entangled with an idea of home as (merely) house, which needs to be transcended if the complexities of home as an active place of negotiation of difference and as a site and concept of belonging are to be elaborated (ibid.: 1998: 6-7).

While feminist migration scholars have begun to redress the balance by turning their attention to domestic and family spaces, gaps remain in the theoretical frameworks adopted. Much of this work asks important questions about the multiplicity of family considerations and connections that form part of migration strategies and how family and work inter-relate (Zontini, 2001, 2004, 2007; Ryan et al., 2009), or draws on social network theories to examine the complexities involved in women negotiating local and transnational networks in the carrying out of reproductive work (Ryan, 2007). But these approaches, focussing as they do on how reproductive works fits into broader processes, tend not to ask too many questions about the specific content of mothering, or to theorize the particular nature of reproductive work.

A second theoretical approach pivots on the notion that migrant women's reproductive work can be characterized as a kind of 'juggling between two worlds'. For example, Ruba Salih's work on Moroccan migrant women in Italy (2001, 2003) provides much fascinating detail of the complexities of home for 
migrant women and the material and emotional work that goes into maintaining transnational links and identities. To analyse her data, Salih draws on Anthony Giddens' concept of 'structuration' to situate these migrant mothers' agency as working within and between the constraints of opposing structures of belonging, pulling them between Morocco and Italy. Yet I feel that this theoretical framework does not go far enough. While it allows us to recognize that migrant women are involved in complex and dynamic work when they mother, it still leaves us with a sense that this work occurs between two, relatively stable sites of belonging, the 'here' and the 'there'. While this certainly captures part of the processes of making home in which migrant mothers are engaged, it does not quite get at the messy, dynamic nature of the reproductive processes and practices involved. What I heard in my focus group's discussions was not just a narrative of juggling between two stable senses of belonging to Africa or to Britain, but also that any site of belonging involves a dynamic entanglement of repetition and innovation. Indeed, as I suggested earlier, achieving stability does not just mean repeating sameness - instead, stability can be represented as necessarily bound up with negotiating change. From this perspective, what goes on in the work of making material and emotional homes is not only a tension between constraining structures and women's agency, and is not just a juggling of two pre-existing and relatively unchanging structures of belonging. The question is not only how migrant mothers are constrained by pre-existing structures in their agency, but also, how can we understand both structures and agents of belonging as messy and dynamic entanglements of constraint and enablement, being and becoming, movement and inhabitance. As Salih herself suggests, if cultural identities are always dynamic and changing, then the work of being 'rooted' in those identities necessarily involves 'historical processes of adaptation, negotiation and reformulation of cultural and religious identities in postcolonial societies' (2003: 124-130). Some of the work on migration by feminist geographers has expanded this insight by drawing on a more fluid and dynamic concept of 'place' (Massey, 1993) and the intricate relationships between body, place and identity (see especially Dyck, 2006). But what could still be made more explicit in this insight is the ways in which reproductive work and the reproductive body are central to these processes. The 'juggling between two worlds' model fails to make this link, because it has an unintended effect of reifying each of the two worlds in question, displacing the dynamic work of reinvention into a 'space between' rather than looking for that dynamism within the work of reproduction and motherhood itself.

A third, related, theoretical approach is to privilege separation and distance as the motor of any dynamism in the reproductive sphere, both in terms of the activities that are the focus of research and in terms of the conceptual frameworks adopted. We see this in the privileging of the 'transnational family' that needs to re-imagine or re-invent itself because it can not rely on the shared 
time or space of day-to-day interaction. A focus on 'mothering at a distance' (Vuorela, 2002; Erel, 2002, 2003) or the mechanisms of sustaining a sense of 'co-presence' and caring relationships in the context of transnational separations (Zontini, 2004; Baldassar, 2008; Ryan, 2008; Svasek, 2008) becomes a way to tell more complicated stories about the reproductive sphere. Concepts such as 'relativizing' and 'frontiering' (Bryceson and Vuorela, 2002) are suggested to theorize the complexities of work to produce a sense of family as 'imagined community' (ibid.: 14) when actual family members are living separated, transnational lives. I am not arguing that these changes in family formation and mothering practices in the context of migration are not important. I do want to ask whether it is necessary to theorize them in ways that seem to reinforce rather than challenge the binary oppositions between movement and inhabitance, distance and proximity. 'Mothering-at-a-distance' is complicated, fascinating work that involves all kinds of complex reinventions of everyday practices to produce a sense of identity and belonging that is never fixed and taken-forgranted. But as my focus group participants suggested, mothering at close quarters can also be characterized in this way. Perhaps with concepts like frontiering and relativizing, Bryceson and Vuorela are too quick to conclude that distance is the key ingredient introducing dynamism to the reproductive sphere.

I find it interesting that Bryceson and Vuorela develop these concepts as a contrast to Avtar Brah's notion of 'diaspora space', which they see as not speaking to questions of family formation, and as emphasizing boundaries and space over aspects of agency and everyday practice (2002: 4-5). What they miss, I think, is Brah's challenge to here/there binaries through her insistence on the entanglement and mutually constitutive nature of genealogies of travel and staying put. While it is true that Brah's work does not expand on issues of family formation or details of everyday practices, the concept of 'diaspora space' might nevertheless enable a different view of what it means to make homes in the context of migration. In Brah's version of diaspora space, 'home' and 'dispersal' are in creative tension so that it is possible to desire and imagine a home, a site of belonging and cohesion, while 'simultaneously critiquing discourses of fixed origins' (Brah, 1996: 192-193). This is an important double move that both recognizes the importance of the work that goes into reproducing home or 'place', and refuses to accept the terms within which home, place and reproduction are defined in dominant discourses. In contrast, an over-emphasis on transnational distances and movement alone can leave those dominant terms of meaning for home, place and reproduction intact.

\section{feminist theories of reproduction}

It is here that feminist theories of reproduction and the reproductive body are of value, for it is precisely in relation to these concepts of home, place and 
reproduction that they have something different to say. Many feminist theories of the body have worked with the idea that birth and maternal subjectivities have been excluded from serious consideration in most of the history of Western philosophy. The French feminist philosopher Luce Irigaray, argues that an 'act of matricide' (Whitford, 1991b) is the founding gesture of Western thought, whereby all possibility of change, dynamism and generation is stripped from the embodied reproductive experiences of women and granted instead to a rational, disembodied masculine subject (Irigaray, 1974). Irigaray has been a key reference point for a critique of Western philosophy's denial of reproduction and for thinking alternative approaches to identity and subjectivity from the perspective of a body that births. This work reveals the recurrence in Western thought of the 'myth of masculine self-birth' (Walker, 1998) through appropriating metaphors of birth for masculine models of being and creativity, while 'simultaneously and repeatedly disavowing maternal origin in its theories and models of subjectivity' (Tyler, 2000: 291). It notes the ways in which dominant discourses of mothering seem to require an absence of self (Lawler, 2000) and omit any consideration of the subjectivity of the mother (Young, 1990). In Irigaray's work, this is linked to the long tradition in Western philosophy of associating the mother with mere 'matter', which must be transcended in order to become a subject of reason. A production/reproduction and thought/matter divide is instated in which masculine production and thought are privileged over the 'mere' matter of reproduction, and this binary underpins much Western philosophy (Walker, 1998). Production opens out to the new, the different, while reproduction is conceptualized only as repetition of the same (ibid.: 166-167). For Irigaray, the woman as mother is positioned as place, the 'still silent ground' (1974: 365) upon which the masculine subject is constituted, and as long as she serves that symbolic function she can not take a place of her own or even take place, that is, exist and define an identity of her own. Thus there is a need to rethink the terms of place itself, since the problem is not only the positioning of the woman/ mother as place, but also the very conceptualization of the place they are said to be - a site of stasis and repetition-as-same against which the dynamism of time is produced.

In order to explore a different way of thinking about the time and place of reproduction, Italian feminist philosopher Adriana Cavarero (1995) revisits the mythic figure of Penelope, the archetypal patient wife keeping the home fires burning for her travelling husband-hero 0dysseus. She pays particular attention to the specificities of the domestic work in which Penelope is engaged as exemplified by 'the unending work of weaving and unweaving' (12) the same shroud, the one task that stands between her and an unwelcome betrayal of her husband through a forced second marriage. Cavarero acknowledges that Penelope's is 'a small story, repetitive and motionless, that reflects the rhythm of a single place' (12). But, she argues that 'Penelope has a symbolic power 
of her own that is open to different readings' (13). Penelope, for Cavarero, 'weaves her quiet time of self-belonging' (14); 'she weaves and unweaves and in so doing delineates an impenetrable space where she belongs to herself' (17), transforming a 'womanly' role into its own liberating rejection (18). Odysseus' story is one of pressing time, a progression of deeds projecting into the future, a 'time of action ... characterized by the new and the unexpected' a time that 'does not belong to the home' (15). Home, for Odysseus, is only a point of departure and return, characterized by the absence of action. By contrast, and in Odysseus' terms, Penelope's time is 'predictable and productive - producing garments, satisfying needs, delivering care' (16). But on her own terms, Penelope is tailoring for herself 'an unpredictable and impenetrable time and space' that is neither the time of 'men's actions' nor the time of 'wifely domestic production': it is 'an infinite repetition' that yet fails to achieve the completeness of domestic production - a rhythmic undoing (17). In unweaving what she has woven, Penelope defines her own time and space, engaging in a process of meaningmaking that is inseparable from the body.

Cavarero's project, like Irigaray's, aims to disrupt the structures of meaning embedded in phallocentric philosophy, in order to find sites of subversion where a philosophy centred on the acknowledgement of birth, rather than the defiance of death, could be imagined, and she understands Penelope's deception as one such potential site. Thus she is looking for resources that could represent a more deliberate rejection of dominant structures of meaning and identity than I am claiming might be inherent in the everyday work of physical and cultural reproduction. Additionally, and particularly problematic for my purposes, both Cavarero and Irigaray privilege sexual difference over other forms of difference. Thus the ways in which sexual difference or gender intersects with race, ethnicity and other forms of cultural difference, fall outside the frame of Cavarero and Irigaray's consideration. This is a particularly significant absence if one wants to think about the connections between physical and cultural reproduction, and the ways in which women's reproductive practices are both mobilized and constrained within discourses of national, ethnic and racialized identities (see Kandiyoti, 1993; Yuval-Davis, 1997). As I have argued elsewhere, the reproductive 'place' that Irigaray claims mothers are meant to be is not just a ground upon which an unspecified masculine subject can stand, but is also a crucial terrain upon which collective identities are constituted and contested (Gedalof, 1999).

Nevertheless, Irigaray and Cavarero's work can make an important contribution to scholarship on migration. In particular, I want to retain two insights from Cavarero. The first is that we question the abiding power of definition of long-standing narrative structures. The ancient myth of Odysseus can be understood as one of those 'founding gestures' of Western thought that associates movement and travel with self-actualization and agency, while relegating the feminized space of the home to insignificance. This is a narrative 
structure that lends itself to stories of migration, but with problematic, gendered consequences, because it focuses only on the productive dislocating aspect of migration while under-valuing the reproductive relocating that migration also necessarily entails. Second, I want to retain Cavarero's insistence that we complicate our understanding of the meaning of repetitive, reproductive practices undertaken within the domestic sphere. For as Cavarero suggests, there is always the possibility of a repetition that undoes, a repetition that communicates agency and produces something new and challenging. By challenging the association between repetition and sameness and opening up the possibility that repetition is not always and only about sameness, Cavarero's retelling of Penelope's story suggests a way to reconceptualize the reproductive work of mothers.

Iris Marion Young develops some of these ideas in a less abstracted way when she argues for a feminist revaluing of home (1997). Young argues that Heidegger's gendered distinction between building and preservation remains influential in the ways the work of making homes is conceptualized. While both are essential, building is associated with making meaning, preservation with the lesser task of maintaining those meanings, and Young argues that 'much of the unnoticed labour of women is this basic activity of meaning maintenance' (1997: 138). This distinction continues to effect feminist thought, as in de Beauvoir's description of housework as 'endless repetition .... The housewife wears herself out marking time: she makes nothing, simply perpetuates the present' (ibid.: 147). In de Beauvoir's scheme of things, the domestic is mired in the realm of immanence, necessary to sustaining life but incapable of being a source of expressions of individuality. The time of immanence is cyclical and repetitive (ibid.: 148). For young, though, 'home enacts a specific mode of subjectivity and historicity that is distinct both from the creative-destructive idea of transcendence and from the ahistorical repetition of immanence' (ibid.: 149). Making home is a materialization of identity through arranging objects in space as an extension of bodily habits and as support to embodied routines, and things in the home carry sedimented personal meanings as retainers of personal narratives (ibid.: 150). Home anchors (without fixing) identity in a physical being that makes a continuity between past and present. Preservation is not just a simple repeating of a meaning made once and for all; rather, the events and achievements materialized through the physical space of home must be 'told and retold, interpreted and reinterpreted', as well as being protected from neglect or damage, if they are to continue to have any meaning at all. Preservation, then, is about renewing meaning, a 'knitting together of today and yesterday' (ibid.: 153). The work of preservation should not be romanticized, as it can be both conservative and re-interpretive (ibid.: 154), but neither should it be dismissed. As with Cavarero, Young is rethinking what can go on in the work of repetition. Unlike de Beauvoir's view, this is not just time and the subject standing still. It is 
through repetition, telling and retelling, that home as a materialization of identities is created; and if that repetition necessarily involves reinterpretation, as in the story told by my focus group, then we need to see those identities and home-spaces as dynamic in their own right.

This way of thinking about domestic spaces and the work that goes on in them is still relatively rare in white Western feminist scholarship. There tends to be much more emphasis on the ways in which women are materially and discursively constrained by what Marsha Marotta has called 'MotherSpace' (2005), in which mothers are disciplined as objects, rather than subjects, and through which both their movements and their identities are confined. Black feminists have been more insistent on complicating this picture, and also on linking women's individual reproductive subjectivities to processes of reproducing collective identities. Patricia Hill Collins (2005) points to the ways in which black mothering involves a dynamic space of reinvention and struggle. For bell hooks (1991), women's role in constructing a stable 'homeplace' where a sense of self and belonging can be affirmed is a necessary part of building communities of radical resistance. As hooks argues, the work of establishing homeplace, of producing domesticity, may well be a 'conventional role' assigned by sexism. But what is important is that black women took this conventional role and expanded it, turning it into a site that exceeds the constraining logic of both sexism and racism (1991: 44). Tracey Reynolds' research on Caribbean mothers in the UK (2005) similarly explores the work of 'memory and re-memory' by mothers to generate a sense of collective cultural belonging and identity (2005: 48).

So it is important not to assume that the work of producing stability is either (a) necessarily about repeating the same or (b) theoretically uninteresting, as so many philosophers seem to have done. Few actual lives can be lived without some sort of stability, as the destructive effects of the constant flux of war, racial and ethnic conflict, natural disaster, or persistent violence remind us. As Nick Gill has argued in relation to asylum seekers, 'stillness', the ability to stay put, can be both the condition for physical and psychological safety in the face of forced mobility, but also the condition for creative personal and political strategies that build more enabling networks and coalitions of community belonging (Gill, 2009). And as feminist theorists of the reproductive body argue, there is a way of thinking about the dynamics of identity-constitution as requiring processes of sedimentation and stabilization. If this is so, then something important is lost when we over-privilege movement and change as generating meanings of migration. Why should distance, separation, moving on and moving away be so privileged in the ways we think about what it means to be a human subject and what it means to act on the world? It should be possible to think about nearness, inter-dependency and the construction of bonds between selves as equally crucial to our sense of self and agency. Feminist migration studies should be able to make a space for valuing the work of preservation and caring, 
and for challenging the ways in which this 'domestic work' is conceptualized in terms of fixity.

Resistance to such alternative views would appear to be related to another issue raised by feminist theories of the reproductive body, which is the conceptualization of the body itself underpinning dominant theories of the subject. This involves both the conceptualizing of the body as something that needs to be transcended - mere matter, as discussed above - but also the model of the body as bounded container for a discrete self/subject that acts upon objects outside it. The clear cut between self and other that drives most theories of the subject requires a body that can be easily distinguished from other bodies. But, on both these counts, the female body would appear to fall short, and in both cases this is related to the question of birth. Women are positioned in much of Western thought as being more bound to and by their bodies than men, and much of the rationale for this mobilizes particular representations of women's reproductive biology. Thus, 'the 'female' subject-position is linked to fleshy continuity, rather than to an autonomous and individualized 'soul' or 'mind' that merely inhabits the flesh' (Battersby, 1998: 10). The female capacity for birth, and pregnant embodiment itself, make a non-sense of the singular, bounded body-subject model and paradigms of self-other relations based on that model (Tyler, 2000).

Battersby, in particular, has been interested in asking what would happen to our models of identity if we take the body that births as norm. She argues that natality as an abstract category allows us to think identities emerging from a play of bodily relationships - an emergence that is not sudden but that occurs over time (1998: 38). Both physical birth and the reproductive work of caring for and nurturing dependents involve not a sudden and decisive cut between self and other, but rather an ongoing relationality in which 'rhythmic repetitions provide the "labour" that allows identity to emerge from conflictual multiplicities' (ibid.: 9). In the patterns of reproductive work, "self" and "other" emerge together through repeated movements that never simply reproduce a "given" that remains "the same", (168). The self is continually established as self through responses, repetitions and habitual movements over time (207), in which 'genuine repetition is recollected forward' (172). Identity, then, 'depends on a repetition that brings into existence (births) an order of events that was already potentially there in the past' (173). The body that births suggests a model in which proximity, repetition and inter-dependence all provide dynamic resources for identity constitution. Thinking the body as bounded, by contrast, becomes a template for exclusionary self-other relations and for how the self deals with difference - securing to itself that which is 'same' while excluding that which is different. The irony is that what goes on in the 'reproductive sphere' should be conceptualized in these terms of repetition-as-same, when the work of reproduction tends to be assigned 
precisely to those embodied subjects who are the least likely to fit this model of bounded embodiment.

The bounded body also becomes a template for thinking the social body and the body politic, and this is also highly pertinent to questions of migration when debates about integration, social cohesion and 'too much diversity' are as high on the political agenda as they are at the moment. While this is a subject that can not be dealt with adequately here, much of the anxiety about migration is underpinned by an assumption that, in this case, collective identity - social stability and cohesion - requires clear boundaries drawn around a space of sameness, currently expressed in terms of 'common values' or 'shared traditions' (Gedalof, 2007). Indeed, many historic and current migration anxieties take reproduction as their stated or implied focus: the repeated fear of the 'overlyfertile' migrant woman who will 'pollute' the native stock (Klug, 1989; Kofman, 1997; Lentin, 2004; Luibheid, 2006); the concern that immigrant women become a vehicle for importing inappropriate and unacceptable family forms (Cheney, 1996); the contemporary focus in tabloid media and policy debates on 'reproductive tourism' and 'uncontrolled migration's' pressures on the social reproductive activities of health, housing and education services (Gedalof, 2007). Challenging the ways in which reproduction is theorized can also, therefore, feed into these policy debates.

\section{reproductive times and spaces in migration}

What, then, might change if we take these insights about the reproductive body and the work of reproduction into account when thinking about migration? It seems to me that they provide important theoretical resources for thinking the feminized spaces and activities of reproduction as part of ongoing processes of generating identities. First of all, if we are thinking about the subject of migration stories, starting from a body that births can be a way of challenging the self/other, sameness/difference, home/away oppositions that, we have seen, can still inform accounts of women's migration. Making central the kinds of nonsingular, relational subjectivity that reproduction entails can lead us to ask different questions about when and where to find the times and spaces of migrant women's agency. Models of agency that privilege distance and separation draw on a gendered model of embodiment to situate agency in the space/time of separation. Thinking about agency from the perspective of an embodied subject that births suggests that it is not necessary to look only to distance, or separation from the familiar, to find motors of transformation. If identities are generated as much through the work of repetition as through taking on the new then what might appear, because of our theoretical preconceptions, as trying to hold on to the familiar, to stay the same, could actually be a much more complicated and dynamic process. Thinking about the possibilities of the 
repetition that undoes, or that recollects forward in order to birth something that is both new and familiar, could be a way of getting at the dynamic messiness of the work of inhabitance that is still rarely articulated in the scholarship on migration.

From this point of view, reproduction in the context of migration is about a complex and dynamic process of identity constitution in which moving and settling are inextricably entangled, a process in which the sudden - the moving from here to there - is only one possible starting point for the intelligent labour that goes on in the work of repetition that recollects forward. Migration stories can begin from a need for stability as much as a need for change. Making homes in the context of migration can be seen as engaging the work of preservation that Young evokes: of knitting together yesterday and today in ways that involve an ongoing rematerializing of identities. It might be the work of displaying objects that bear meanings of the past in new spatial settings, and not presuming that we know what meanings of place are produced through that placement. It can include the work of making food from 'home' with slightly different ingredients, grown in different climates or with just that gap of time between production and consumption that bends their taste or presentation, served in different rooms, on different dishes, and reflecting on whether this is a repetition that 'reproduces a "given" that remains "the same", (Battersby, 1998), or one that necessarily opens out to difference. It is marking time through the 'same' family and cultural rituals taking place in a different context that requires endless subtle re-inventions and adaptations to a different range of possible private and public spaces, appropriate dress and adornment, food and drink, etc. It can also involve making these daily, multiple decisions about what we and our families wear, how we adorn our bodies or do not, what we do with our hair, while the eye adjusts to subtly changing aesthetic criteria based on the range of possibilities presented to us in the new spaces we find ourselves in. It can embrace stepping far outside of the familiar - in terms of work, family arrangements of childcare and living together or apart, and when and how one's traditional ways of doing things can be passed on - in order to hold on to something that counts materially and emotionally as stability. As my focus group's narrative suggested, this is not without conflict. Sometimes change is embraced and absorbed into a sense of culture as ever-dynamic; at other times, the sense of loss of something more authentic is more troubling. The point, however, is that these everyday acts of embodied repetition can be represented as important sites of the kind of 'conflictual multiplicities' (Battersby, 1998) from which identities emerge.

What is also important is that the 'we' evoked here can be said to include some who have always stayed put, but whose sense of individual and collective self is also being incrementally shifted by the changes brought about by migration processes to the reproductive spaces/places in which they find themselves. When 
anxieties about shared values and a common culture being undermined by migration are focused in large part around perceived strains on the reproductive sphere, including forms of family life and access to health, housing and social care, we need theoretical resources to argue against a reified vision of that reproductive sphere. This is another reason why the familiar 'juggling between two worlds' model is inadequate, because it leaves intact the idea that the world of 'those who are constructed and represented as indigenous' (Brah, 1996) is isolated from, and untouched by the diaspora spaces emerging through processes of migration. Challenging the reification of the reproductive sphere also means undercutting exclusionary and static models of 'indigenous' cultures and the work that is done in the domestic space to reproduce them.

Transnational and migration studies have largely looked to processes of displacement and non-belonging for the sites in which new identities emerge; when feminists take on these models to think about women's specific positioning and activities, they add important insights to the field. We need to know how women construct migrant and transnational identities in the face of processes of displacement, non-belonging and isolation. But are we only hearing Odysseus' narrative of agency - still making the hero(ine) of migration narratives the uprooted, dislocated and solo actor remaking her identity in a new world. What about a migrant Penelope's story of emplacement, belonging and connectedness? Can we unpick the complexities of her small stories to reveal another site in which identities are made? Penelope's repetitive gestures, looked at from this different perspective, reveal a 'kind of intelligence inseparable from the body ... the intelligence of everyday experience, constantly mindful of the need to create a sense of roots and space' (Cavarero, 1995: 123, fn2), while simultaneously complicating how we think about the nature of those roots and spaces. Similarly, the stories of the migrant women I listened to offered a way in to an expanded understanding of the entanglement of repetition and change involved in the work of mothering. Rethinking the place and nature of reproduction could prove a useful resource for feminist migration studies in understanding the work migrant mothers undertake in order to reproduce home, and the place of that home in the making and remaking of new identities.

\section{acknowledgements}

I thank the two anonymous reviewers for their very helpful comments, Imogen Tyler for reading and commenting on more versions of this article than should be expected of any human being, Parminder Sidhu for research assistance in organising the focus group, and the four focus group participants for collectively constructing a richly complicated story to think about. 


\section{author biography}

Irene Gedalof is Senior Lecturer in Women's Studies at London Metropolitan University. She has published work in the areas of identity, power and female embodiment and the intersections of gender, race and ethnicity in Western and postcolonial feminist theory. She is the author of Against Purity: Rethinking Identity with Western and Indian Feminisms (1999) and of articles published in the Journal of Ethnic and Migration Studies, European Journal of Women's Studies and Women: A Cultural Review. Her current research is on questions of home, identity and belonging in representations of migrant women and their practices of cultural reproduction.

\section{references}

Ahmed, S. Castaneda, C., Fortier, A., and Sheller, M. (2003) editors, Uprootings/Regroundings: Questions of Home and Migration, Oxford: Berg.

Baldassar, L. (2008) 'Missing kin and longing to be together: emotions and the construction of co-presence in transnational relationships' Journal of Intercultural Studies, Vol. 29, No. 3: 247-266.

Battersby, C. (1998) The Phenomenal Woman: Feminist Metaphysics and the Patterns of Identity, Cambridge: Polity.

Borland, K. (2004) 'That's not what I said: interpretive conflict in oral narrative research' in Hesse-Biber, S.N. and Leavy, P. (2004) editors, Approaches to Qualitative Research: a Reader on Theory and Practice, Oxford: Oxford UP.

Brah, A. (1996) Cartographies of Diaspora, London and Ny: Routledge.

Bryceson, D. and Vuorela, U. (2002) 'Transnational families in the twenty-first century' in Bryceson, D. and Vuorela, U. (2002) editors, The Transnational Family: New European Frontiers and Global Networks, Oxford and NY: Berg.

Cameron, D. (2001) Working with Spoken Discourse, London: Sage.

Cavarero, A. (1995) In Spite of Plato: A Feminist Rewriting of Ancient Philosophy, Cambridge: Polity.

Chambers, I. (1994) Migrancy, Culture, Identity, London and Ny: Routledge.

Cheney, D. (1996) 'Those whom the immigration law has kept apart let no one join together: a view on immigration incantation' in Jarrett-Macauley, D. (1996) editor, Reconstructing Womanhood, Reconstructing Feminism, London and NY: Routledge, 58-84.

Craig, M.L. (2006) 'Race, beauty and the tangled knot of a guilty pleasure' Feminist Theory, Vol. 7, No. 2: 159-177.

Dyck, I. (2006) 'Travelling tales and migratory meanings: South Asian migrant women talk of place, health and healing' Social and Cultural Geography, Vol. 7, No. 1: 1-18.

Erel, U. (2002) 'Re-conceptualising motherhood: the experiences of some women of Turkish background in Germany' in Bryceson, D. and Vuorela, U. (2002) editors, The Transnational Family, Oxford: Berg.

Erel, U. (2003) 'Gendered and racialized experiences of citizenship in the life stories of women of Turkish background in Germany' in Andall, J. (2003) editor, Gender and Ethnicity in Contemporary Europe, Oxford: Berg.

Gedalof, I. (1999) Against Purity: Rethinking Identity with Indian and Western Feminisms, NY and London: Routledge. 
Gedalof, I. (2007) 'Unhomely homes: women, family and belonging in UK discourses of migration and asylum' Journal of Ethnic and Migration Studies, Vol. 33, No. 1: 77-94.

Gill, N. (2009) 'Longing for stillness: the forced movement of asylum seekers' $M / C$ Journal, 12. I (March 2009), http://journal.media-culture.org.au/index.php/mcjournal/article/view/ 123, accessed 08 June 2009.

Gray, B. (1999) 'The home of our mothers and our birthright for ages?: nation, diaspora and Irish women' in Maynard, M. and Purvis, J. (1999) editors, New Frontiers in Women's Studies, London: Taylor and Francis.

Gunaratnam, y. (2003) Researching 'Race' and Ethnicity, London: Sage.

Hill Collins, P. (2005) 'Black Women and Motherhood' in Hardy, S. and Weidman, C. (2005) editors, Motherhood and Space: Configurations of the Maternal through Politics, Home and the Body, Ny and Basingstoke: Palgrave, 149-159.

Hooks, b. (1991) Yearning, London: Turnaround.

Irigaray, L. (1974) Speculum of the Other Woman, Gillian C Gill (trans.), Ithaca, Ny: Cornell University Press (1985).

Jaworski, A. and Coupland, N. (1999)(editors) The Discourse Reader, London and Ny: Routledge.

Kandiyoti, D. (1993) 'Identity and its discontents' in Chrisman, L. and Williams, P. (1993) editors, Colonial Discourse and Post-Colonial Theory, London: Harvester Wheatsheaf, 376-392.

Klug, F. (1989) 'Oh to be in England: the British case study' in Yuval Davis, N. and Anthias, F. (1989) editors, Woman-Nation-State, Basingstoke: Macmillan, 16-35.

Kofman, $\boldsymbol{\varepsilon}$. (1997) 'When society was simple: gender and ethnic divisions and the far and new right in France' in Charles, N. and Hintjens, H. (1997) editors, Gender, Ethnicity and Political Ideologies, NY and London: Routledge, 91-106.

Lawler, S. (2000) Mothering the Self: Mothers, Daughters, Subjects, Ny and London: Routledge.

Lentin, R. (2004) 'Strangers and strollers: feminist notes on researching migrant m/others' Women's Studies International Forum, Vol. 27: 301-314.

Luibheid, $\boldsymbol{\varepsilon}$. (2006) 'Sexual regimes and migration controls: reproducing the Irish nation-state in transnational contexts' Feminist Review, Vol. 83: 60-79.

Marotta, M. (2005) 'MotherSpace: disciplining through the maternal and the discursive' in Hardy, S. and Weidman, C. (2005) editors, Motherhood and Space: Configurations of the Maternal through Politics, Home and the Body, Ny and Basingstoke: Palgrave, 15-33.

Massey, D. (1993) 'Power-geometry and a progressive sense of place' in Bird, J., Curtis, B., Putnam, T. and Tickner, L. (1993) editors, Mapping the Futures: Local Cultures, Global Change, London and NY: Routledge, 59-69.

Morgan, D. (2004) 'Focus groups' in Hesse-Biber, S. and Leavy, P. (2004) editors, Approaches to Qualitative Research, Oxford: Oxford University Press, 263-285.

Puwar, N. (2002) 'Multicultural fashion' Feminist Review, Vol. 71: 63-87.

Rapport, N. and Dawson, A. (1998) editors, Migrants of Identity: Perceptions of Home in a World of Movement, Oxford: Berg.

Reynolds, T. (2005) Caribbean Mothers: Identity and Experience in the UK, London: Tufnell Press.

Ryan, L. (2007) 'Migrant women, social networks and motherhood: the experiences of Irish nurses in Britain' Sociology, Vol. 41, No. 2: 295-312.

Ryan, L. (2008) 'Navigating the emotional terrain of families "Here" and "There": women, migration and the management of emotions' Journal of Intercultural Studies, Vol. 29, No. 3: 299-313.

Ryan, L., Sales, R., Tilki, M. and Siara, B. (2009) 'Family strategies and transnational migration: recent Polish migrants in London' Journal of Ethnic and Migration Studies, Vol. 35, No. 1: 61-77.

Salih, R. (2001) 'Moroccan migrant women: transnationalism, nation-states and gender' Journal of Ethnic and Migration Studies, Vol. 27, No. 4: 655-671. 
Salih, R. (2003) 'Shifting meanings of Islam and multiple representations of modernity: the case of Muslim women in Italy' in Andall, J. (2003) editor, Gender and Ethnicity in Contemporary Europe, Oxford: Berg.

Svasek, M. (2008) 'Who cares?: families and feelings in movement' Journal of Intercultural Studies, Vol. 29, No. 3: 213-230.

Tate, S. (2007) 'Black beauty: shade, hair and anti-racist aesthetics' Ethnic and Racial Studies, Vol. 30, No. 2: 300-319.

Tyler, I. (2000) 'Reframing pregnant embodiment' in Ahmed, S., Kilby, J., Lury, C., McNeil, M. and Skeggs, B. (2000) editors, Transformations: Thinking Through Feminism, NY and London: Routledge.

Vuorela, U. (2002) 'Transnational Families: Imagined and Real Communities' in Bryceson, D. and Vuorela. U (2002) editors, The Transnational Family: New European Frontiers and Global Networks, Oxford and Ny: Berg, 63-82.

Walker, M.B. (1998) Philosophy and the Maternal Body, London and Ny: Routledge.

Webster, W. (1998) Imagining Home: Gender, 'Race' and National Identity, 1945-1964, London: UCL Press.

Weekes, D. (1997) 'Shades of Blackness: young black female constructions of beauty' in Mirza, H. (1997) editor, Black British Feminisms: A Reader, Ny and London: Routledge, 113-126.

Whitford, M. (199la) The Irigaray Reader, Oxford: Blackwell.

Whitford, M. (1991b) Luce Irigaray: Philosophy in the Feminine, London and Ny: Routledge.

Young, I.M. (1990) Throwing Like a Girl and Other Essays, Bloomington: Indiana University Press.

Young, I.M. (1997) Intersecting Voices: Dilemmas of Gender, Political Philosophy and Policy, Princeton: Princeton UP.

Yuval-Davis, N. (1997) Gender and Nation, London: Sage.

Zontini, $\boldsymbol{\varepsilon}$. (2001) 'Family formation in gendered migrations: Moroccan and Filipina women in Bologna' in King, R. (2001) editor, The Mediterranean Passage: Migration and New Cultural Encounters in Southern Europe, Liverpool: Liverpool UP.

Zontini, $\boldsymbol{\varepsilon}$. (2004) 'Immigrant women in Barcelona: coping with the consequences of transnational Life' Journal of Ethnic and Migration Studies, Vol. 30, No. 6: 1113-1144.

Zontini, $\boldsymbol{\varepsilon}$. (2007) 'Continuity and change in transnational Italian families: the caring practices of second-generation women' Journal of Ethnic and Migration Studies, Vol. 33, No. 7: 1103-1119.

doi: $10.1057 / f r .2009 .23$ 